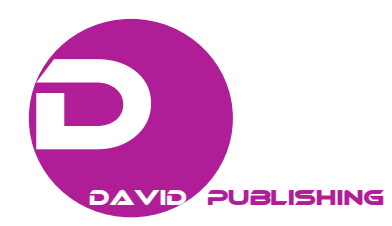

\title{
The Impacts of Climate Change on Fitzroy River Basin, Queensland, Australia
}

\author{
Nahlah Abbas ${ }^{1}$, Saleh A. Wasimi ${ }^{1}$, Surya Bhattarai ${ }^{2}$ and Nadhir Al-Ansari ${ }^{3}$ \\ 1. School of Engineering and Technology, Central Queensland University, Melbourne 3000, Australia \\ 2. School of Medical and Applied Sciences, Central Queensland University, Melbourne 3000, Australia \\ 3. Geotechnical Engineering, Lulea University of Technology, Lulea 971 87, Sweden
}

\begin{abstract}
An analysis of historical data of Fitzroy River, which lies in the east coast of Australia, reveals that there is an increasing trend in extreme floods and droughts apparently attributable to increased variability of blue and green waters which could be due to climate change. In order to get a better understanding of the impacts of climate change on the water resources of the study area for near future as well as distant future, SWAT (soil and water assessment tool) model was applied. The model is first tested for its suitability in capturing the basin characteristics with available data, and then, forecasts from six GCMs (general circulation model) with about half-a-century lead time to 2046 2064 and about one-century lead time to 2080 2100 are incorporated to evaluate the impacts of climate change under three marker emission scenarios: A2, A1B and B1. The results showed worsening water resources regime into the future.
\end{abstract}

Key words: Fitzroy basin, climate change, water resources, SWAT.

\section{Introduction}

Australia is one of the driest continents in the world and recognized as one of the most vulnerable to climate change [1]. The continent has a high degree of rainfall variability and experiences extreme weather events such as floods and droughts which are likely to aggravate by climate change [2]. Although evidences are growing supporting correlation between climate change and its effects on water availability, few studies on this subject are available in Australia [3]. The interaction between climate and water issues is not yet adequately understood [2], and therefore, one of the aims of this study has been to get an insight into the relationship between climate change and water availability in Australia. The Fitzroy River Basin, the largest river basin on the east coast and the second largest seaward-draining catchment in Australia, was chosen as the study area. The mathematical tool SWAT

Corresponding author: Nadhir Al-Ansari, professor, research fields: water resources and environment. E-mail: nadhir.alansari@ltu.se. (soil and water assessment tool) was applied since it has found widespread application throughout the world [4], and after calibration and validation, GCM model outputs were used to delineate future water regimes.

\section{Study Area}

The Fitzroy River Basin extends from the city of Rockhampton to Carnarvon Gorge National Park in the west, and drains an area of approximately $142,645 \mathrm{~km}^{2}$ (10\% of Queensland's land area) to the southern end of the GBR (Great Barrier Reef) [5]. Originally most of the catchment was dominated by brigalow (Acacia harpophylla) forest and other ecosystems such as eucalypt forests, grasslands and riparian communities, but these were cleared in the 1960s and 1970s [6].

The basin comprises the catchment of the Fitzroy River and its major tributaries: Nogoa, Comet, Connors-Isaac, Dawson, and Mackenzie Rivers [7] (Fig. 1). Nogoa River is in the far west of the basin, flowing through Emerald and later links with Theresa Creek that comes from the northwest at Clermont. Comet River drains the south-central part of the basin 


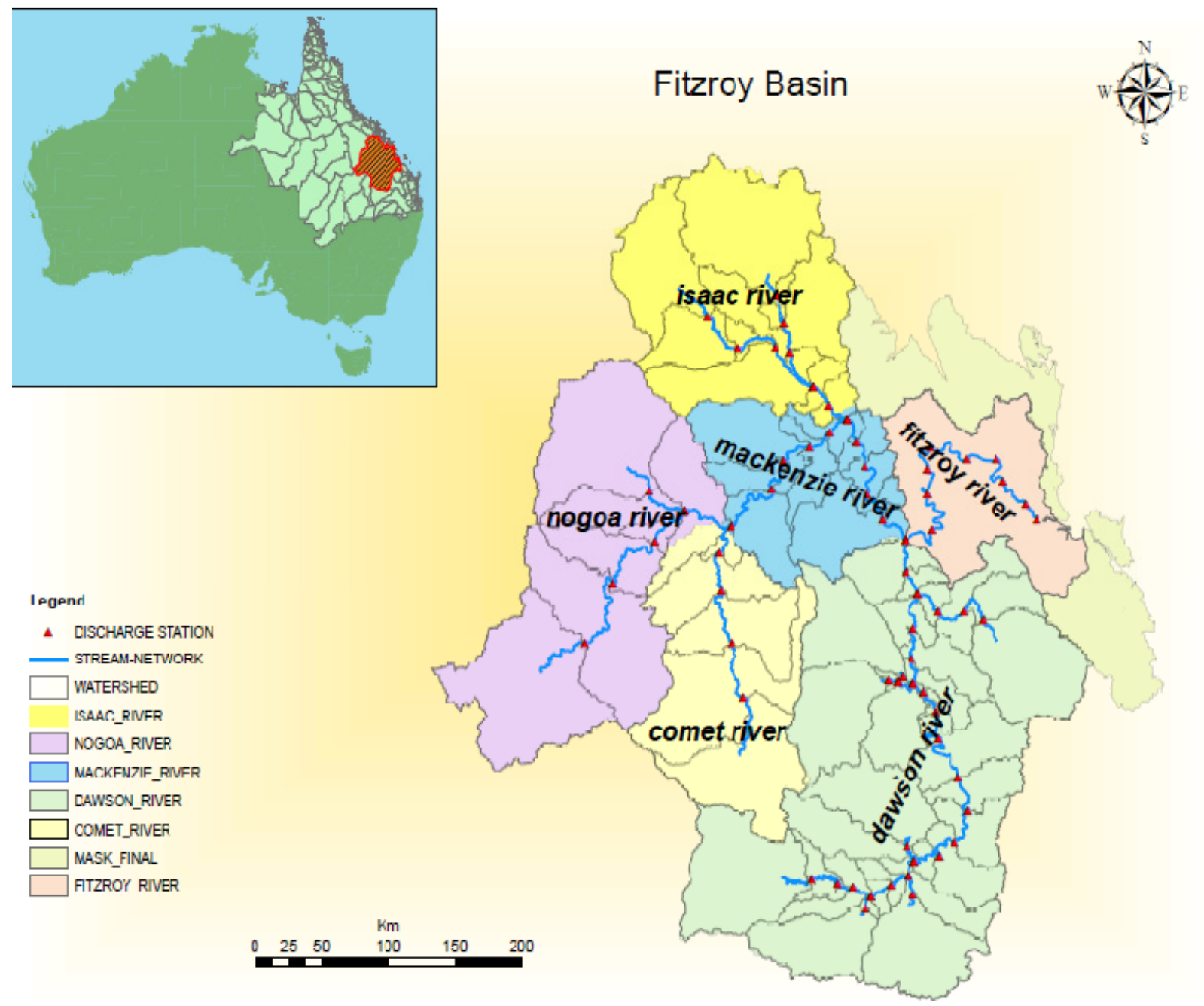

Fig. 1 Location of Fitzroy River catchment.

and then combines with Nogoa forming Mackenzie River. Connor-Isaac River drains the northern part of the basin and then is joined by Mackenzie just upstream of the Tartarus Weir. Dawson River drains the southern part of the basin and joins Mackenzie further downstream. The combined stream is referred to as Fitzroy River which debouches into the southern Pacific Ocean approximately $60 \mathrm{~km}$ downstream of Rockhampton [8].

The climate of the Fitzroy Basin is tropical to sub-tropical, ranging from semi-arid inland to humid near the coast, with wet summers and mild to dry winters [6]. The mean annual temperature varies from $19.2{ }^{\circ} \mathrm{C}$ in the south to $22.6^{\circ} \mathrm{C}$ in the north. There is a high level of rainfall variability within the catchment due to climatic drivers such as El Niño-ENSO (Southern Oscillation) and the PDO (Pacific Decadal Oscillation) [9]. Mean annual rainfall ranges with higher rainfall areas close to the coast from $1,800 \mathrm{~mm}$ in the east to $600 \mathrm{~mm}$ in the west. Rainfall is mostly linked to the tropical monsoon, with occasional widespread heavy rainfall from tropical cyclones from the Coral Sea off the east coast of Queensland [6]. Flows are highly variable within and between years, greater than $90 \%$ of flow occurs in the wet season from December to May [9].

The soils of the Fitzroy Basin are very diverse owing to large variations in lithology, climate and geomorphic processes. There are more than 100 soil types recorded present in the catchment and no one soil group is 
dominant [8].

The most common land use in the catchment is grazing. Large areas of dry-land cropping are present in the western part of the basin, whereas irrigated cropping occurs in the towns of Emerald, Theodore and Biloela. An extensive coal mining is occurring in the Bowen Basin, especially around the towns of Moranbah, Dysart, Blackwater and Moura [8].

The Fitzroy Basin is of significant importance to Queensland, considered as one of the richest areas in the state due to its land, minerals and water resources, and supports industry sectors such as grazing, agriculture, mining, forestry and tourism [8]. It contains approximately $10 \%$ of the state's agricultural land [8]. This basin is the main source of freshwater to approximately 185,000 people or $5.3 \%$ of the state's population [7]. Water demand is expected to increase as population is projected to grow rapidly [7]. Climate change is presumed to enhance water issues in this region [5].

\section{Description of SWAT Model}

The SWAT model [4], used in this study, is a river watershed scale, semi-distributed and physics-based discrete time (daily computational time step) model for analyzing hydrology and water quality at various watershed scales with varied soils, land use and management conditions on a long-term basis. The model was originally developed by the USDA (United States Department of Agriculture) and the ARS (Agricultural Research Service). SWAT system is embedded within a geographic information system (ArcGIS interface) in which different spatial environmental data, including climate, soil, land cover and topographic characteristics can be integrated.

Two major modules, land phase and routing phase, are run to simulate the hydrology of a watershed. The land phase of the hydrological cycle predicts the hydrological components including surface runoff, evapotranspiration, groundwater, lateral flow, and return flow. The routing phase of the hydrological cycle is the movement of water, sediments, nutrients and organic chemicals via the channel network of the basin to the outlet. The estimation of surface runoff is done through two methods; the SCS (Soil Conservation Service) curve number procedure [4] and the Green and Ampt infiltration method [10]. The SCS method has been used in this study due to non-availability of sub-daily data that is required by the Green and Ampt infiltration method. The model estimates the volume of lateral flow depending on the variation in conductivity, slope and soil water content. A kinematic storage model is utilized to predict lateral flow through each soil layer. Lateral flow occurs below the surface when the water rates in a layer exceed the field capacity after percolation.

The groundwater simulation is divided into two aquifers which are a shallow aquifer (unconfined) and a deep aquifer (confined) in each watershed. The shallow aquifer contributes to stream flow in the main channel of the watershed. Water that percolates into the confined aquifer is presumably contributing to stream flow outside the watershed. Three methods are provided by SWAT model to estimate potential evapotranspiration (PET) - the Penman-Monteith method, the Priestley-Taylor method and the Hargreaves method. Water is routed through the channel network by applying either the variable storage routing or Muskingum River routing methods using the daily time step.

Enormous amount of input data are required by SWAT model to fulfill the tasks envisaged in this research. Basic data requirements for modeling included DEM (digital elevation model), land use map, soil map, weather data and discharge data. Data were compiled from different sources. DEM data was obtained from Queensland Department of Natural Resources and Mines with a $25 \mathrm{~m}$ grid and $1 \mathrm{~km}$ spatial resolution. ${ }^{1}$ The land cover map was obtained from

\footnotetext{
${ }^{1}$ https://data.qld.gov.au/dataset/digital-elevation-models-25metr e-by-catchment-areas-series/resource/2a35f 233-cb03-4c2f-9e9 $1-177785 \mathrm{fbc} 916$.
} 
Queensland Government ${ }^{2}$ with a $50 \mathrm{~m}$ grid raster for the period of 1999 to 2009 . The soil map was collected from the global soil map of the Food and Agriculture Organization of the United Nations [11]. Weather data including daily precipitation, 0.5 hourly precipitation, maximum and minimum temperatures were obtained from the Australian government's Bureau of Meteorology website. ${ }^{3}$ Daily stream flow data was collected from Queensland Department of Natural Resources and Mines/Water Monitoring Portal. ${ }^{4}$

In SWAT model, the watershed is divided into sub-basins based on the DEM. The land use map, soil map and slope datasets were embedded within the SWAT databases. Thereafter, sub-basins are further subdivided by HRUs (Hydrologic Response Units). HRUs are defined as packages of land that have a unique slope, soil and land use area within the borders of the sub-basin. HRUs enable the user to identify the differences in hydrologic conditions such as evapotranspiration for varied soils and land uses. Routing of water and pollutants are predicted from the HRUs to the sub-basin level and then through the river system to the watershed outlet.

To evaluate the performance of the SWAT model, the sequential uncertainty fitting algorithm application (SUFI-2) embedded in the SWAT-CUP package [12] was used. The advantages of SUFI-2 are that it combines optimization and uncertainty analysis, can handle a large number of parameters through Latin hypercube sampling and it is easy to apply. Furthermore, as compared with different techniques in connection to SWAT such as GLU (generalized likelihood uncertainty) estimation, ParSol (parameter solution), MCMC (Markov Chain Monte Carlo), SUFI-2 algorithm was found to obtain good prediction uncertainty ranges with a few number of runs. This efficiency is of great significance when implementing

\footnotetext{
${ }^{2}$ https://www.dnrm.qld.gov.au/water/catchments-planning/catc hments/Fitzroy.

${ }^{3} \mathrm{http} / / / \mathrm{www} \cdot$ bom.gov.au/climate/data/.

${ }^{4}$ https://www.dnrm.qld.gov.au/water/water-monitoring-and-dat a/portal.
}

complex and large-scale models.

The SUFI-2 first identifies the range for each parameter. After that, Latin hypercube method is used to generate multiple combinations among the calibration parameters. Finally, the model runs with each combination and the obtained results are compared with observed data until the optimum objective function is achieved. Since the uncertainty in forcing inputs (e.g., temperature, rainfall), conceptual model and measured data are unavoidable in hydrological models, the SUFI-2 algorithm computes the uncertainty of the measurements, the conceptual model and the parameters by two measures: $P$-factor and $R$-factor. $P$-factor is the percentage of data covered by the $95 \%$ prediction uncertainty (PPU) and the $\mathrm{R}$-factor is the average width of the 95 PPU divided by the standard deviation. Further, SUFI-2 calculates the coefficient of determination $\left(R^{2}\right)$ and the ENC (Nasch-Sutcliff efficiency) [13] to assess the goodness of fit between the measured and simulated data.

SUFI-2 enables users to conduct global sensitivity analysis, which is computed based on the Latin hypercube and multiple regression analysis. The multiple regression equation is defined as below:

$$
g=\alpha+\sum_{i=1}^{m} \beta_{i} * b_{i}
$$

where, $g$ is the value of evaluation index for the model simulations, $\alpha$ is a constant in multiple linear regression equation, $\beta$ is a coefficient of the regression equation, $b$ is a parameter generated by the Latin hypercube method and $m$ is the number of parameters. Both $t$ and $p$ values in statistical methods are used to indicate parameter sensitivity.

\section{GCM (General Circulation Model) Inputs}

Six GCMs from CMIP3 namely CGCM3.1/T47, CNRM-CM3, GFDL-CM2.1, IPSLCM4, MIROC3.2 (medres) and MRI CGCM2.3.2 were selected for climate change projections in the Fitzroy River Basin under a very high emission scenario (A2), a medium 
emission scenario (A1B) and a low emission scenario (B1) for atmospheric temperature and precipitation, which were then inputted to SWAT model calibrated for the Fitzroy River catchment. Then comparisons were made with the baseline period (1980 2010) for water resources. BCSD (bias corrected spatial downscaling) method was used to downscale the GCM results [14].

\section{Results and Discussion}

\subsection{Sensitivity Analysis}

Sensitivity analysis was conducted for 25 parameters related to stream flow from which 12 most sensitive parameters were selected for simulation for the Fitzroy. The 12 parameters are listed in Table 1.

$C N 2$ was the most sensitive parameter. ALPHA-BE was observed to be the second highest sensitive parameter and the most sensitive parameter among ground water parameters. $G W \_D E L A Y$ was ranked the third.

\subsection{Calibration and Validation}

The model was calibrated on a monthly scale for twenty two years (1979 2000) and validated for 10 years (2001 2010) and the first 3 years was used as a warm up at eight different discharge stations located within the catchment. Measured and simulated monthly flow at all discharge stations in the basin matched well in both calibration and validation processes as shown in Table 2.

\subsection{Impacts of Climate Change on Air Temperature and Precipitation}

Prior to identifying the impacts of climate change on water resources in the Fitzroy Basin, mean annual temperature and precipitation outputs from the six GCMs

Table 1 Most sensitive parameters (ranked) related to stream flow in the Fitzroy Basin.

\begin{tabular}{llll}
\hline Parameter & Rank & Initial values & Fitted values \\
\hline$C N 2$ & 1 & $-0.2 \sim 0.2$ & -0.14 \\
ALPHA_BF & 2 & $0 \sim 1$ & 0.87 \\
GW_DELAY & 3 & $30 \sim 450$ & 389 \\
CH_K2 & 4 & $5 \sim 130$ & 33.9 \\
OV-N & 5 & $-0.2 \sim 0$ & -0.16 \\
HRU_SLP & 6 & $0 \sim 0.2$ & 0.01 \\
ESCO.hru & 7 & $0.8 \sim 1$ & 0.83 \\
REVAPMN & 8 & $0 \sim 10$ & 4 \\
GW_REVAP & 9 & $0 \sim 0.2$ & 0.023 \\
SLSUBBSN & 10 & $0 \sim 0.2$ & 0.11 \\
SOL_AWC & 11 & $-0.2 \sim 0.4$ & -0.045 \\
GWQMN & 12 & $0 \sim 2$ & 1.45 \\
\hline
\end{tabular}

Table $2 R^{2}$ and $E N C$ values in calibration and validation processes at monthly scale at eight discharge stations in Fitzroy Basin.

\begin{tabular}{|c|c|c|c|c|c|}
\hline \multirow{2}{*}{ Basin } & \multirow{2}{*}{ Station } & \multicolumn{2}{|c|}{ Calibration } & \multicolumn{2}{|c|}{ Validation } \\
\hline & & $\overline{R^{2}}$ & $E N C$ & $\overline{R^{2}}$ & $E N C$ \\
\hline Isaac & Yatoon & 0.73 & 0.73 & 0.66 & 0.62 \\
\hline Comet & The Lake & 0.69 & 0.66 & 0.89 & 0.53 \\
\hline Dawson & Riverslea & 0.58 & 0.50 & 0.66 & 0.52 \\
\hline Dawson & Redcliffe & 0.58 & 0.56 & 0.84 & 0.66 \\
\hline Dawson & Taroom & 0.77 & 0.76 & 0.87 & 0.73 \\
\hline Nogoa & Gregory & 0.85 & 0.83 & 0.82 & 0.77 \\
\hline Mackenzie & Coolmaringa & 0.69 & 0.67 & 0.8 & 0.76 \\
\hline Fitzroy & The Gap & 0.73 & 0.67 & 0.87 & 0.87 \\
\hline
\end{tabular}


were processed for three scenarios (A2, A1B, B1). Table 3 captures the projected changes in mean annual temperature for two future periods (2046 2064) and (2080 2100) relative to base period (1980 2010). Changes in mean temperature tend to be less disperse than precipitation. All the models showed consistent increasing trends in temperature over Fitzroy Basin under the three scenarios (A2, A1B, B1). As expected, B1 Scenario showed the lowest increases which is expected to be up to $0.71{ }^{\circ} \mathrm{C}$ and $1.15{ }^{\circ} \mathrm{C}$ for the near future and the distant future, respectively. By contrast, A2 Scenario projected the highest increases up to $1.05{ }^{\circ} \mathrm{C}$ and $2.6^{\circ} \mathrm{C}$ for the period of 2046 to 2064 and 2080 to 2100 , respectively. These results are consistent with results of Rolfe and Windle [15] who found that, in Australia by 2070 , projected average annual temperature may rise by $1{ }^{\circ} \mathrm{C}$ to $2.5{ }^{\circ} \mathrm{C}$ for low greenhouse gas emissions and $2.2{ }^{\circ} \mathrm{C}$ to $5{ }^{\circ} \mathrm{C}$ for high emissions. MRI-CGCM 2.3.2 model projected the lowest average annual temperature while GFDL-CM2.1 projected the highest temperature (Table 3).

Fig. 2 shows the anomaly maps of precipitation distribution (maps of percent deviation from historic data, 1980 2010) for A2, A1B and B1 Scenarios for the periods 2046 2064 and 2080 2100 for the average change of multi-GCM ensemble. All scenarios show an increase in precipitation trend for the near and distant future for the most basins except small part of Nogoa Basin which will experience reduction up to $10 \%$ under
A2 Scenario for the period (2046 2064). B1 Scenario projected the highest increases in near and distant futures, $11 \%$ and $23 \%$, respectively. A1B projected increase of $8 \%$ and $12 \%$ for the period of 2046 2064 and 2080 2100, respectively. A2 showed increases of $3 \%$ and $6 \%$ for near and distant futures, respectively. Isaac Basin will experience the highest increase under B1 Scenario for the both periods. These outcomes confirm the results of earlier study of Yu and Joo [16], they predicted that this region will likely be wetter due to longer and more intense monsoon resulting from more intense atmospheric convection especially Isaac Basin due to its close location to the coast.

\subsection{Impacts of Climate Change on Blue and Green Waters}

Blue and green waters patterns generally follow precipitation pattern. Blue and green waters tend to be high where precipitation is high. Fig. 3 shows the anomaly maps of blue water distribution (maps of percent deviation from historic data, 1980 2010) for A2, A1B and B1 Scenarios for the periods 2046 2064 and 2080 2100 for the average change of multi-GCM ensemble. Similar to precipitation trend, all scenarios show an increase in blue water trend for the near and distant futures for most basins except a small part of Nogoa basin which will experience reduction up to 10\% under A2 Scenario for the period 2046 2064. A2 showed increases of $7 \%$ and $27 \%$ for near and distant futures, respectively. A1B projected increase of 35\%

Table 3 Projected atmospheric temperature increases in the future from various GCMs.

\begin{tabular}{|c|c|c|c|c|c|c|}
\hline \multirow{2}{*}{ Periods } & \multicolumn{6}{|c|}{ Annual change in mean temperature $\left({ }^{\circ} \mathrm{C}\right)$} \\
\hline & CGCM3.1/T47 & CNRM-CM3 & GFDL-CM2.1 & PSLCM4 & MIROC3.2 & MRICGCM2.3.2 \\
\hline \multicolumn{7}{|l|}{$\mathrm{A} 2$} \\
\hline $2046 \sim 2064$ & 1.08 & 1.13 & 1.24 & 1.11 & 0.91 & 0.83 \\
\hline $2080 \sim 2100$ & 2.47 & 2.47 & 3.37 & 2.76 & 2.20 & 2.20 \\
\hline \multicolumn{7}{|l|}{$\bar{A}$ A1B } \\
\hline $2046 \sim 2064$ & 1.12 & 1.29 & 1.24 & 1.26 & 0.86 & 0.76 \\
\hline $2080 \sim 2100$ & 1.67 & 1.95 & 2.16 & 2.39 & 1.89 & 0.83 \\
\hline \multicolumn{7}{|l|}{ B1 } \\
\hline $2046 \sim 2064$ & 0.67 & 0.72 & 0.99 & 0.86 & 0.53 & 0.51 \\
\hline $2080 \sim 2100$ & 1.16 & 1.28 & 1.28 & 1.12 & 1.16 & 0.94 \\
\hline
\end{tabular}




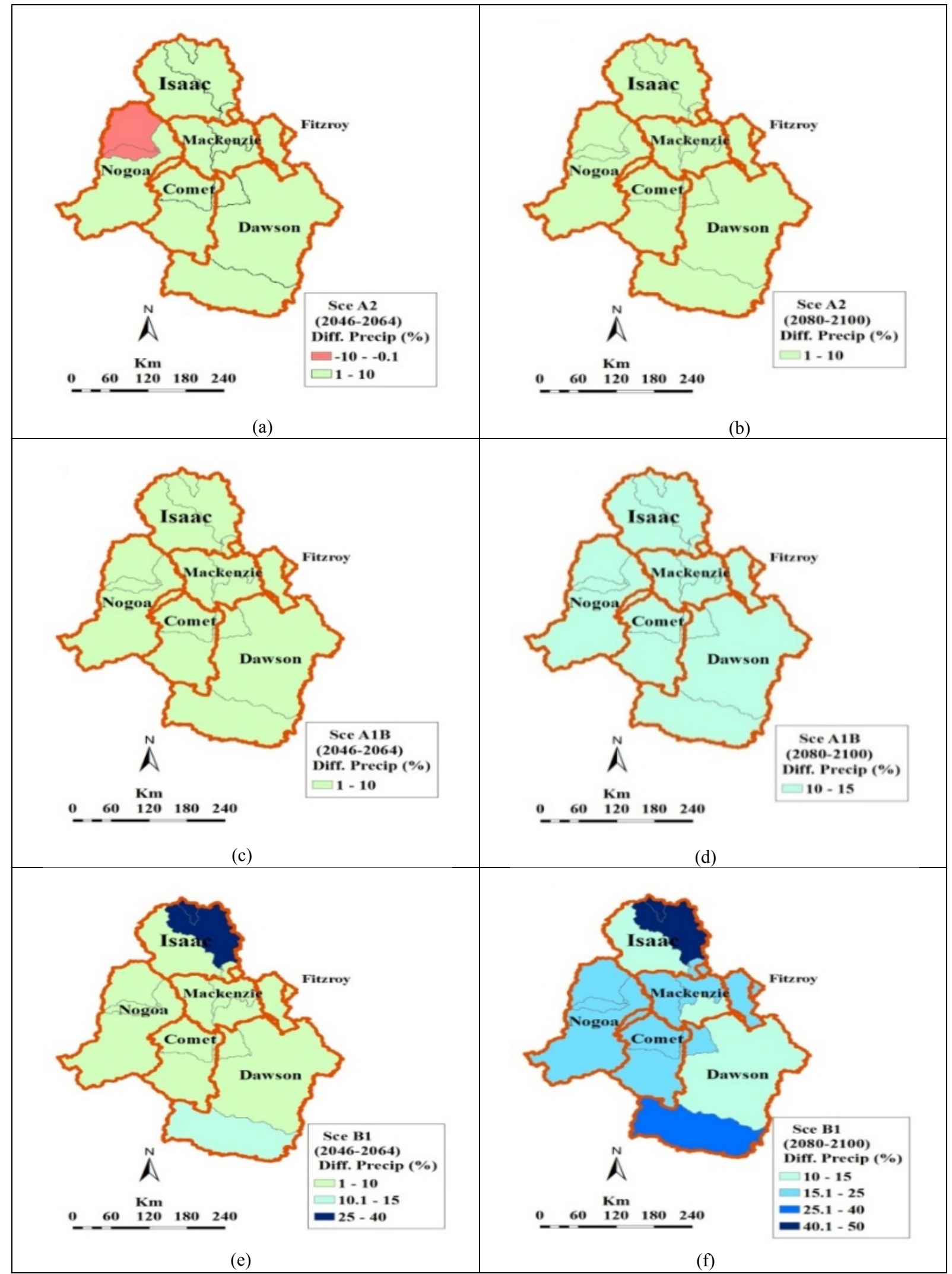

Fig. 2 The impacts of climate change on the precipitation of the basin: (a) anomaly based on Scenario A2 for the period of 2046 2064; (b) anomaly for A2 to 2080 2100; (c) anomaly for A1B to 2046 2064; (d) anomaly for A1B to 2080 2100; (e) anomaly for B1 to 2046 2064; and (f) anomaly for B1 to 2080 2100. 


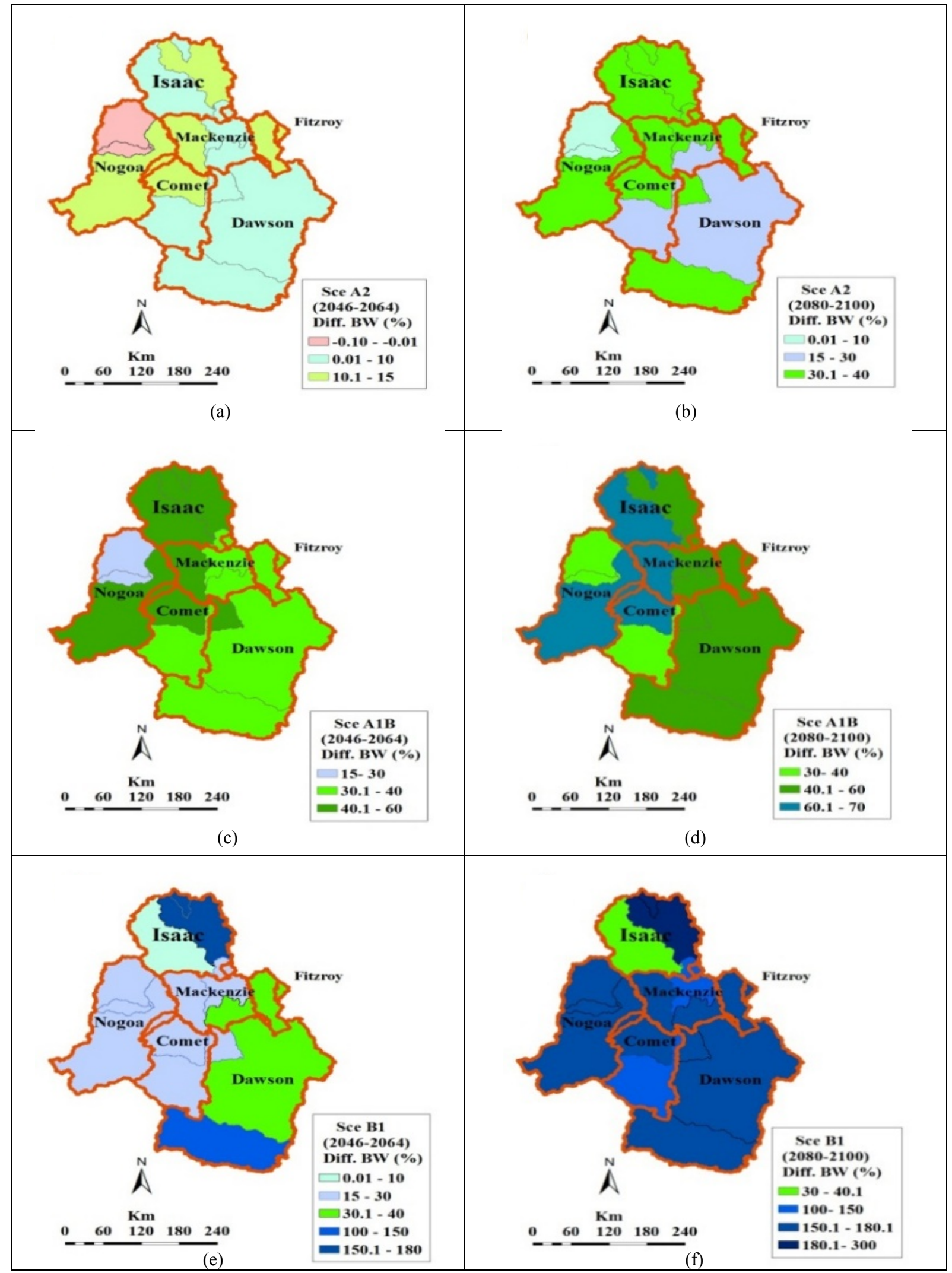

Fig. 3 The impacts of climate change on blue water of the basin: (a) anomaly based on Scenario A2 for the period of 2046 2064; (b) anomaly for A2 to 2080 2100; (c) anomaly for A1B to 2046 2064; (d) anomaly for A1B to 2080 2100; (e) anomaly for B1 to 2046 2064; and (f) anomaly for B1 to $2080 \sim 2100$. 


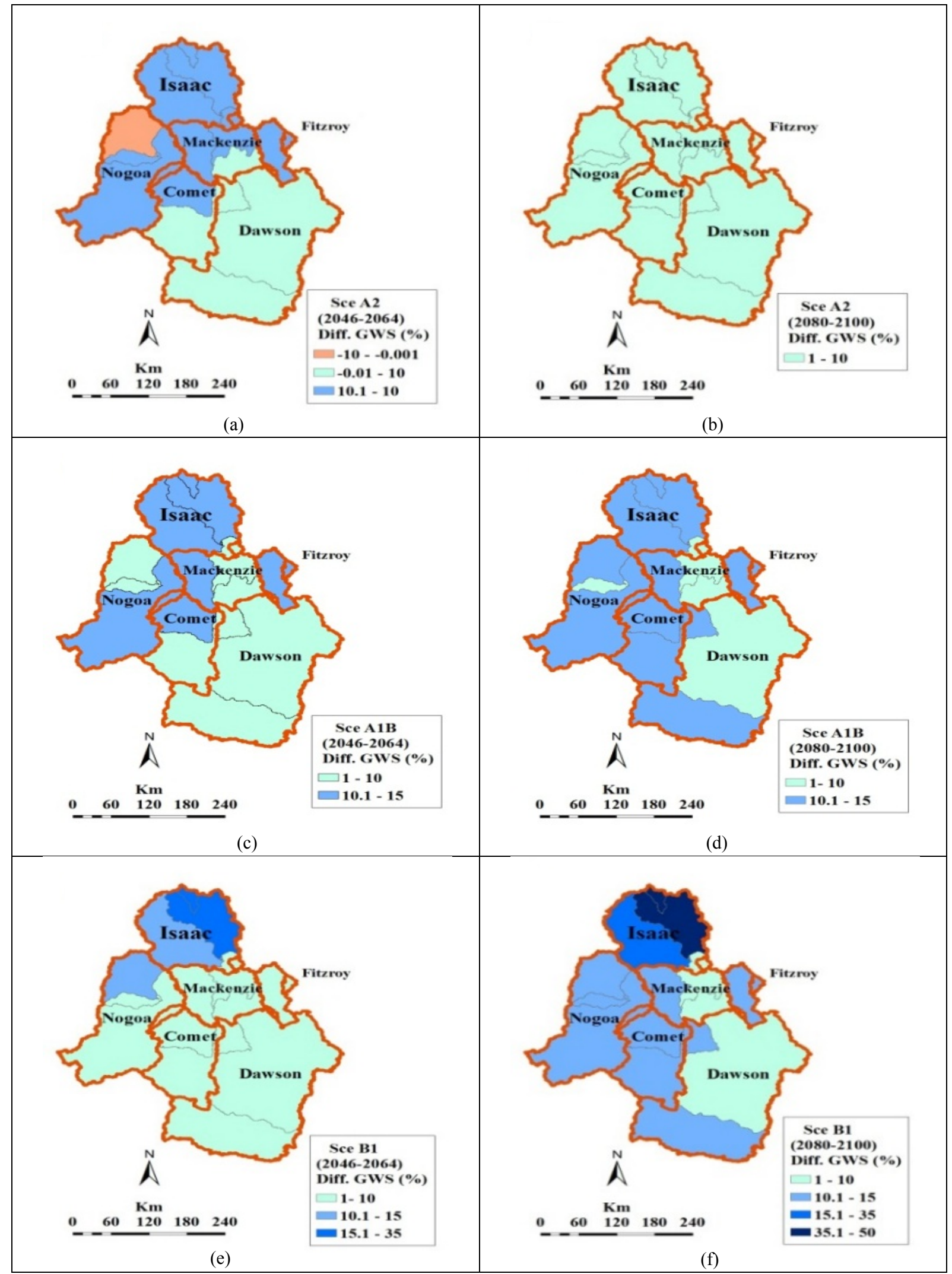

Fig.4 The impacts of climate change on green water of the basin: (a) anomaly based on Scenario A2 for the period of 2046 2064; (b) anomaly for A2 to 2080 2100; (c) anomaly for A1B to 2046 2064; (d) anomaly for A1B to 2080 2100; (e) anomaly for B1 to 2046 2064; and (f) anomaly for B1 to $2080 \sim 2100$. 
and 52\% for the period of 2046 2064 and 2080 2100, show an increase in blue water trend for the near and distant futures for most basins, respectively. B1 Scenario projected increases in near and distant future of $50 \%$ and $110 \%$, respectively. Isaac Basin will experience the highest increase under B1 Scenario for the both period.

Fig. 4 captures the green water storages which manifest similar trends as blue water.

\section{Conclusions}

SWAT model was applied to the Fitzroy Basin at monthly time steps. The model was calibrated and validated at eight discharge stations to simulate the stream flow. The performance of the model was found to be satisfactory with $R^{2}$ and $E N C$ indices during the calibration and validation periods. The calibrated model was applied for assessing the impacts of climate change on temperature, precipitation, blue and green waters in the near future (2046 2064) and distant future (2080 2100) under three emission scenarios (A2, A1B, B1) using six GCMs. All models predicted that the catchment will be hotter and wetter in the near and distant futures except a small part in Nogoa Basin located in the north of the basin under A2 in near future. The impact on blue water appears to be more pronounced than green water, which may imply higher degree of worsening in flood situations than drought situations.

\section{References}

[1] Abbaspour, K., Yang, J., Maximov, I., Siber, R., Bogner, K., Mieleitner, J., Zobrist, J., and Srinivasan, R. 2007. "Modelling Hydrology and Water Quality in the Pre-alpine/Alpine Thur Watershed Using SWAT." Journal of Hydrology 333 (2): 413-30.

[2] Arnold, J. G., Srinivasan, R., and Williams, M. 1998. "Large Area Hydrologic Modeling And Assessment Part I: Model Development 1." Journal of the American Water Resources Association 34 (1): 73-89.

[3] Chambers, L. E., Hughes, L., and Hughes, C. 2005. "Climate Change and Its Impact on Australia's Avifauna." Journal of Bird Life Australia 105 (1): $1-20$.
[4] Cobon, D., and Zhang, N. T. 2007. "Climate Change Impacts on the Sediment Load for the Nogoa Catchment of the Fitzroy Basin." Presented at the MODSIM 2007 International Congress on Modelling and Simulation, Queensland.

[5] Dougall, C. 2014. Modelling Reductions of Pollutant Loads due to Improved Management Practices in the Great Barrier Reef Catchments. Technical report, Department of Natural Resource and Mines, Rockhampton.

[6] FAO (Food and Agriculture Organization). 1995. The Digital Soil Map of the World and Derived Soil Properties. Version 3.5. Rome: FAO.

[7] Green, W. H., and Ampt, G. 1911. "Studies on Soil Physics, 1. The Flow of Air and Water through Soils." Journal of Agriculture Science 4: 1-24.

[8] Head, L., Adams, M., McGregor, H. V., and Toole, S. 2014. "Climate Change and Australia." Wiley Interdisciplinary Reviews: WIREs Climate Change 5 (2): 175-97.

[9] Hughes, L. 2003. "Climate Change and Australia: Trends, Projections and Impacts." Journal of Austral Ecology 28 (4): 423-43.

[10] IPCC (International Panel on Climate Change). 2007. Impacts, Adaptation and Vulnerability. Contribution of Working Group II to the Fourth Assessment report of the Intergovernmental Panel on Climate Change, Cambridge University Press.

[11] Lough, J. M. 2007. "Tropical River Flow and Rainfall Reconstructions from Coral Luminescence: Great Barrier Reef, Australia." Accessed August 13, 2007. http://onlinelibrary.wiley.com/doi/10.1029/2006PA00137 7/pdf.

[12] Maurer, E. P., Brekke, L., Pruitt, T., Thrasher, B., Long, J., Duffy, P., Dettinger, M., Cayan, D., and Arnold, J. 2014. "An Enhanced Archive Facilitating Climate Impacts and Adaptation Analysis." Bulletin of the American Meteorological Society 95 (7): 1011-9.

[13] Nash, J., and Sutcliffe, J. V. 1970. "River Flow Forecasting through Conceptual Models Part I-A Discussion of Principles." Journal of Hydrology 10 (3): 282-90.

[14] Nicholls, W., and Lavery, D. 1997. “Australian Rainfall Variability and Change." Weather 52 (3): 66-72.

[15] Rolfe, J., and Windle, A. K. 2004. "Overview of the Fitzroy Basin and Opportunities for Offset Trading." Establishing The Potential for Offset Trading in the Lower Fitzroy River Research Reports (1), Queensland.

[16] Yu, B., and Joo, M. 2013. "Land use and water quality trends of the Fitzroy River, Australia, Sweden.” Presented at IAHS IAHS-IAPSO-IASPEI Joint Assembly 2013, Gothenburg, Sweden. 